Pacific Journal of Mathematic 


\title{
AN INEQUALITY FOR SUBORDINATE ANALYTIC FUNCTIONS
}

\author{
EDGAR REICH
}

1. Introduction. If $f(z)$ and $F(z)$ are nonconstant analytic functions, regular in the unit circle $|z|<1$, then $f(z)$ is called subordinate to $F(z)$, written

$$
f(z) \prec F(z),|z|<1,
$$

provided there exists a function $\omega(z)$, regular in the unit circle, with

$$
\omega(0)=0,|\omega(z)|<1 \text {, and } f(z)=F[\omega(z)] .
$$

The concept of subordination has proved useful in studies of the range of values of analytic functions [2, pp.163-171]. The following interesting result has recently been established by G.M. Goluzin [ 1]:

Goluzin's Theorem. Let

$a(r)=$ area of the region on the Riemann surface onto which the disk $|z|<r$ is mapped by $f(z)$,

and

$A(r)=$ area of the region on the Riemann surface onto which the disk $|z|<r$ is mapped by $F(z)$.

Then

$$
a(r) \leq A(r) \text { for } r \leq \frac{1}{\sqrt{2}}
$$

further, if $r<1 / \sqrt{2}$, equality in (2) can be achieved only in the trivial case

Received April 7, 1953. The results of this paper form part of a Ph.D. thesis, the problem considered having been suggested to the author by Professor E. F. Beckenbach of the University of California, Los Angeles.

Pacific J. Math. 4 (1954), 259-274 


$$
\omega(z)=\eta z \cdot^{1}
$$

It should be remarked that Goluzin's Theorem is intuitively obvious for the case where $\omega(z)$ is schlicht, for then the Riemann surface corresponding to $|z|<r$ under $f(z)$ is a subset of the corresponding surface for $F(z)$, and (2) is therefore obtained for any $r<1$. If $\omega(z)$ is not restricted to be schlicht, the example

$$
f(z)=z^{2}, F(z)=z
$$

shows that (2) does not always hold for all $r<1$; in fact for this case, as pointed out by Goluzin,

$$
a(r)>A(r) \text { for any } r>\frac{1}{\sqrt{2}},
$$

while

$$
a\left(\frac{1}{\sqrt{2}}\right)=A\left(\frac{1}{\sqrt{2}}\right),
$$

so that the range $0 \leq r \leq 1 / \sqrt{2}$ is the best possible one for the inequality ( 2 ).

2. Theorem. In this paper we extend Goluzin's Theorem to the complete interval $0 \leq r<1$; that is, we explicitly find a universal function $T(r)$ (which turns out to be a continuous function of $r$, made up of arcs of polynomials), such that, for any $f(z), F(z)$ satisfying (1),

$$
\frac{a(r)}{A(r)} \leq T(r)
$$$$
(0 \leq r<1) \text {, }
$$

where we denote $\lim _{r \rightarrow 0} a(r) / A(r)$ by $a(0) / A(0)$, and where the inequality $(3)$ is the best possible one, in the sense that for any $r(0 \leq r<1)$ it is possible to find a pair of functions $f(z), F(z)$, satisfying (1), such that (3) is an equality for that particular $r$. (Of course, it follows from Goluzin's Theorem that $T(r)=1$ for $0 \leq r^{2} \leq 1 / 2$.) We supplement our result by making a complete enumeration of the function pairs $[f(z), F(z)]$ for which equality in $(3)$ can be achieved. The final result is as follows.

THEOREM. The function $T(r)$ is given by the formula value.

${ }^{1}$ In this paper $\eta$ always denotes an arbitrary complex constant of unit absolute 


$$
T(r)=m r^{2 m-2}
$$

in the range

$$
\frac{m-1}{m} \leq r^{2} \leq \frac{m}{m+1}
$$

Equality in (3) for a given $r$ is possible under, and only under, the following circumstances:

(i) $r^{2}<1 / 2$ and $\omega(z)=\eta z$ (as remarked above);

(ii) $r^{2}=1 / 2$, and either

$$
\omega(z)=\eta z
$$

or

$$
F(z)=C_{0}+C_{1} z, f(z)=C_{0}+C_{1} \eta z^{2}
$$

(iii) $\frac{m-1}{m}<r^{2}<\frac{m}{m+1}$

(5)

and

$$
F(z)=C_{0}+C_{1} z, f(z)=C_{0}+C_{1} \eta z^{m}
$$

(iv) $r^{2}=\frac{m}{m+1}$

and either

$$
F(z)=C_{0}+C_{1} z, f(z)=C_{0}+C_{1} \eta z^{m}
$$

or

$$
F(z)=C_{0}+C_{1} z, f(z)=C_{0}+C_{1} \eta z^{m+1} .
$$

It is very easy to check that for the cases listed above one actually obtains equality in (3), so that if (3) can be shown to be generally true it follows that it is the best possible inequality.

Since $f(z)=0$ and $|f(z)|<1$ imply that $f(z) \prec z$, we can, as an application of the theorem, immediately state the following: 
COROLLARY. If $f(z)=0$ and $|f(z)|<1$ for $|z|<1$, then

$$
a(r) \leq \pi m r^{2 m}
$$

in the range

$$
\frac{m-1}{m} \leq r^{2} \leq \frac{m}{m+1}
$$

This is the best possible inequality. [The cases of equality can be obtained by putting $C_{0}=0, C_{1}=1$ in (5)].

3. Lemmas. Before proceeding with the proof proper of the theorem we shall state some known results, and derive some others.

The following notation will be adopted as standard:

$$
\begin{gathered}
f(z)=c_{0}+c_{1} z+c_{2} z^{2}+\cdots, \quad F(z)=C_{0}+C_{1} z+C_{2} z^{2}+\cdots, \\
\omega(z)=\beta_{1} z+\beta_{2} z^{2}+\cdots
\end{gathered}
$$

Thus

$$
c_{0}=C_{0} \text {. }
$$

Furthermore, as an easy computation shows,

$$
a(r)=\pi \sum_{k=1}^{\infty} k\left|c_{k}\right|^{2} r^{2 k}, \quad A(r)=\pi \sum_{k=1}^{\infty} k\left|C_{k}\right|^{2} r^{2 k}
$$

Lemma $1[2]$. If $\omega(z) \not \equiv \eta z$, then $\left|c_{1}\right|<\left|C_{1}\right|,\left|\beta_{1}\right|<1$.

This is an immediate consequence of the Lemma of Schwarz.

LEMma $2[2] .\left|\beta_{2}\right| \leq 1-\left|\beta_{1}\right|^{2}$.

This is proved by applying the Lemma of Schwarz to the function

$$
\frac{\omega(z) / z-\beta_{1}}{1-\bar{\beta}_{1} \omega(z) / z} \text {. }
$$

Lemma $3[2] . \max _{|z|=r}|f(z)| \leq \max _{|z|=r}|F(z)|$ 
Also a consequence of Schwarz's Lemma.

\section{EMMA 4 .}

(6)

$$
\sum_{k=1}^{\infty}\left|c_{k}\right|^{2} r^{2 k} \leq \sum_{k=1}^{\infty}\left|C_{k}\right|^{2} r^{2 k}
$$

This is a special case of a more general inequality for mean values of arbitrary nonnegative order on the circle $|z|=r$. The proof by Littlewood [2] uses subharmonic functions. A different proof has been given by Goluzin [1].

LEMMA 5. If

$$
s_{n}=\sum_{k=1}^{n}\left|c_{k}\right|^{2}, S_{n}=\sum_{k=1}^{n}\left|C_{k}\right|^{2}
$$

then

$$
s_{n} \leq S_{n}
$$

with equality for a particular $n$ implying that

$$
c_{n+1}=\beta_{1}^{n+1} C_{n+1}
$$

The inequality $(7)$ is a known result [1], but we shall repeat the proof to show how (8) follows.

Proof. Let

$$
s_{n}(z)=\sum_{k=1}^{n} c_{k} z^{k}, S_{n}(z)=\sum_{k=1}^{n} C_{k} z^{k}, R_{n}(z)=\sum_{k=n+1}^{\infty} C_{k} z^{k} .
$$

Then

$$
\begin{aligned}
C_{0}+s_{n}(z)+\sum_{n+1}^{\infty} c_{k} z^{k}=f(z)=F(\omega(z)) & =S_{n}(\omega(z))+R_{n}(\omega(z))+C_{0} \\
& =C_{0}+S_{n}(\omega(z))+\sum_{n+1}^{\infty} c_{k}^{(n)} z^{k}
\end{aligned}
$$


where

$$
c_{n+1}^{(n)}=C_{n+1} \beta_{1}^{n+1}
$$

and so on. We have

$$
S_{n}(\omega(z))=s_{n}(z)+\sum_{n+1}^{\infty} d_{k}^{(n)} z^{k}
$$

where

$$
d_{k}^{(n)}=c_{k}-c_{k}^{(n)}
$$

so that, for example,

$$
d_{n+1}^{(n)}=c_{n+1}-C_{n+1} \beta_{1}^{n+1} \text {. }
$$

Now, by the fundamental definition of subordination,

$$
S_{n}[\omega(z)] \prec S_{n}(z)
$$

Therefore, using (6) in the equation above, we have

$$
\sum_{1}^{n}\left|c_{k}\right|^{2} r^{2 k}+\sum_{n+1}^{\infty}\left|d_{k}^{(n)}\right|^{2} r^{2 k} \leq \sum_{1}^{n}\left|C_{k}\right|^{2} r^{2 k} .
$$

Thus ( 7 ) follows, and equality certainly implies

$$
d_{n+1}^{(n)}=c_{n+1}-C_{n+1} \beta_{1}^{n+1}=0
$$

as was to be shown.

\section{LEMMA 6 [1]. If $\left\{\lambda_{k}\right\}$ are such that}

$$
\lambda_{k} \geq 0, \lambda_{k} \geq \lambda_{k+1}
$$

then

$$
\sum_{k=1}^{\infty} \lambda_{k}\left|c_{k}\right|^{2} \leq \sum_{k=1}^{\infty} \lambda_{k}\left|C_{k}\right|^{2}
$$


Proof by partial summation, using Lemma 5.

Lemma 6.1. Under the hypothesis (9), and with $s_{n}$ and $S_{n}$ defined by (7), equality in (10) implies

$$
\left(\lambda_{k}-\lambda_{k+1}\right) \cdot\left(S_{k}-s_{k}\right)=0 \quad(k=1,2, \cdots) .
$$

Proof. Let

$$
r_{n}=\sum_{k=1}^{n} \lambda_{k}\left|c_{k}\right|^{2}, R_{n}=\sum_{k=1}^{n} \lambda_{k}\left|C_{k}\right|^{2}, s_{0}=S_{0}=0 .
$$

The hypothesis is

$$
\lim _{n \rightarrow \infty}\left(R_{n}-r_{n}\right)=0
$$

Thus

$$
\begin{aligned}
0 & =\lim _{n \rightarrow \infty}\left[\sum_{k=1}^{n} \lambda_{k}\left(S_{k}-S_{k-1}\right)-\sum_{k=1}^{n} \lambda_{k}\left(s_{k}-s_{k-1}\right)\right] \\
& =\lim _{n \rightarrow \infty}\left[\sum_{k=1}^{n} \lambda_{k} S_{k}-\sum_{k=0}^{n-1} \lambda_{k+1} S_{k}-\sum_{k=1}^{n} \lambda_{k} s_{k}+\sum_{k=0}^{n-1} \lambda_{k+1} s_{k}\right] \\
& =\lim _{n \rightarrow \infty}\left[\sum_{k=1}^{n-1}\left(\lambda_{k}-\lambda_{k+1}\right) S_{k}+\lambda_{n} S_{n}-\sum_{k=1}^{n-1}\left(\lambda_{k}-\lambda_{k+1}\right) s_{k}-\lambda_{n} s_{n}\right] \\
& =\lim _{n \rightarrow \infty}\left[\sum_{k=1}^{n-1}\left(\lambda_{k}-\lambda_{k+1}\right)\left(S_{k}-s_{k}\right)+\lambda_{n}\left(S_{n}-s_{n}\right)\right] .
\end{aligned}
$$

Since the terms in the square brackets are all nonnegative, (11) follows.

Lemma 7. If

(i) $f(z)=c_{0}+c_{1} z+c_{2} z^{2} \prec F(z)=c_{0}+C_{1} z+C_{2} z^{2}$,

(ii) $\left|c_{1}\right|<\left|C_{1}\right|$,

(iii) $\left|c_{1}\right|^{2}+\left|c_{2}\right|^{2}=\left|C_{1}\right|^{2}+\left|C_{2}\right|^{2}$, 
then

$$
f(z)=c_{0}+C_{1} \eta z^{2}, F(z)=c_{0}+C_{1} z .^{2}
$$

Proof. As indicated by (ii), we have $\left|C_{1}\right|>0$, so we can normalize as follows:

$$
f(z)=c_{1} z+c_{2} z^{2}, F(z)=z+C_{2} z^{2} .
$$

Let

$$
p=\left|c_{1}\right|, q=\left|c_{2}\right|, Q=\left|C_{2}\right| \text {. }
$$

We have, according to (ii) and (iii),

$$
\begin{aligned}
p & <1, \\
p^{2}+q^{2} & =1+Q^{2} .
\end{aligned}
$$

Now

$$
\max _{|z|=1}\left|c_{1} z+c_{2} z^{2}\right|=\left|c_{1}\right|+\left|c_{2}\right|=p+q,
$$

as is obvious if $c_{1}=0$, and follows by taking $z=e^{-i \arg \left(c_{2} / c_{1}\right)}$ if $c_{1} \neq 0$. Similarly,

$$
\max _{|z|=1}\left|z+C_{2} z^{2}\right|=1+Q
$$

Applying Lemma 3, we get

$$
p+q \leq 1+Q
$$

The shaded triangle $O L_{1} L_{2}$ in the facing figure corresponds to the inequality (16). The quarter-circle $P_{1} P_{2} P_{3}$ corresponds to the equality (15); $P_{1}$ lies below $L_{1}$, and $P_{3}$ to the left of $L_{2}$, because

$$
\sqrt{1+Q^{2}} \leq 1+Q \text { for any } Q \geq 0 \text {. }
$$

The circle and the hypotenuse of the triangle intersect in two points with coordinates $(Q, 1)$ and $(1, Q)$, respectively (merging into a single point if $Q=1)$.

${ }^{2}$ A more general result is stated, but not proved, in a footnote on page 56 of Rogosinski's paper [3]. 
When $Q \geq 1$, the point $L_{3}$ in the figure has the coordinates $(1, Q)$, and $L_{4}$ has coordinates $(Q, 1)$. When $Q \leq 1$, then $L_{3}=(Q, 1), L_{4}=(1, Q)$. In either case, (14) dictates that eligible points $(p, q)$ lie to the left of $L_{4}$, and therefore on the arc $P_{1} L_{3}$. Therefore, since the ordinate of $L_{3}$ is never less than 1 , it is always true that

$$
q \geq 1
$$

We proceed by considering two cases:

(I) $Q=0$,

(II) $Q>0$,

and show that (II) leads to a contradiction. Thus, assume $Q>0$. We have

$$
c_{1} z+c_{2} z^{2}=\omega+C_{2} \omega^{2}, \quad C_{2} \neq 0 .
$$

Therefore

$$
\omega(z)=\frac{\left.-1+\sqrt{1+4 C_{2}\left(c_{1} z+c_{2} z^{2}\right.}\right)}{2 C_{2}},
$$

where, since $\omega(z)$ is regular in $|z|<1$, we must have

$$
1+4 C_{2}\left(c_{1} z+c_{2} z^{2}\right) \neq 0 \quad(|z|<1),
$$

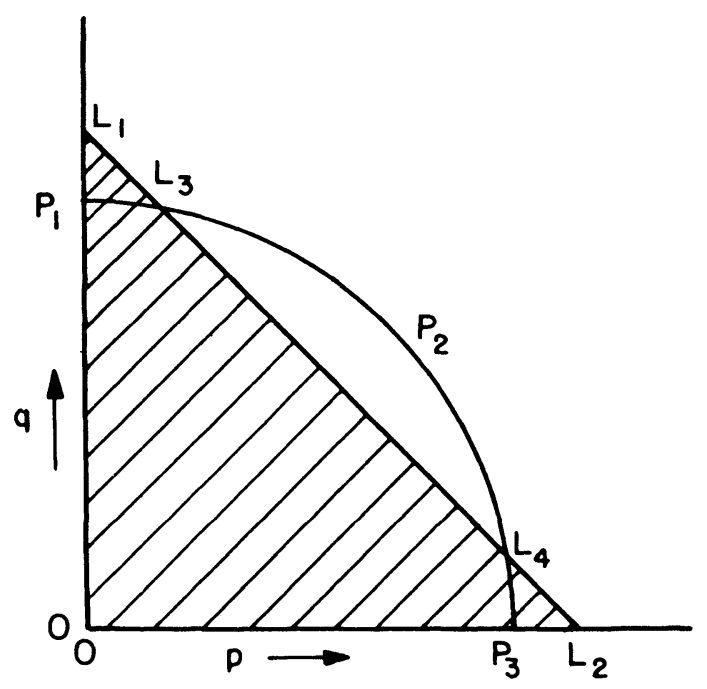


and we must take that branch of $\omega(z)$ which equals zero for $z=0$. Let $z_{1}, z_{2}$ be the roots of (19). Since (19) is to have no roots for $|z|<1$, we have

$$
\left|z_{1}\right| \geq 1,\left|z_{2}\right| \geq 1
$$

and therefore, by (19),

$$
1 \leq\left|z_{1} z_{2}\right|=\left|\frac{1}{4 c_{2} C_{2}}\right|=\frac{1}{4 q Q},
$$

or, in view of (17),

$$
Q \leq 1 / 4 \text {. }
$$

The next step consists in applying Lemma 2. By (18),

$$
\beta_{1}=\omega^{\prime}(0)=c_{1}, \beta_{2}=\frac{1}{2} \omega^{\prime \prime}(0)=c_{2}-c_{1}^{2} C_{2} \text {. }
$$

Thus, by Lemma 2,

$$
\left|c_{2}-c_{1}^{2} C_{2}\right| \leq 1-\left|c_{1}\right|^{2} \text {, }
$$

and so

$$
\left|c_{2}\right|-\left|c_{1}^{2} C_{2}\right| \leq 1-\left|c_{1}\right|^{2}
$$

that is,

$$
q+p^{2}(1-Q) \leq 1 .
$$

But $q \geq 1$ by (17), and $1-Q>0$ by (20). Therefore

$$
q=1 \text { and } p=0 \text {. }
$$

Equation (15) now implies $Q=0$, showing the impossibility of (II).

Since (I) is the only alternative to (II), we may conclude that

$$
Q=\left|C_{2}\right|=0 \text {. }
$$

Then (14), (15), (17), (22) jointly imply

$$
q=1 \text { and } p=0 .
$$


Therefore, by ( 13 ),

$$
\omega(z)=\eta z^{2}
$$

and (12) now follows.

L.ЕMMA 8. Let $m$ be a fixed positive integer, $t$ a fixed positive real number, and $k$ a positive integer. The following relations hold:

(i) for any $k$, if $\frac{m-1}{m} \leq t \leq \frac{m}{m+1}$, then $m t^{m} \geq k t^{k}$;

(ii) if $k \leq m, t \geq \frac{m-1}{m}$, then $\left\{k t^{k}\right\}_{k}$ is an increasing sequence;

(iii) if $k \leq m, t>\frac{m-1}{m}$, then $\left\{k t^{k}\right\}_{k}$ is a strictly increasing sequence;

(iv) if $k \leq m-1, t \geq \frac{m-1}{m}$, then $\left\{k t^{k}\right\}_{k}$ is a strictly increasing sequence;

(v) if $k \geq m, t \leq \frac{m}{m+1}$, then $\left\{k t^{k}\right\}_{k}$ is a decreasing sequence;

(vi) if $k \geq m_{\diamond} t<\frac{m}{m+1}$, then $\left\{k t^{k}\right\}_{k}$ is a strictly decreasing sequence;

(vii) if $k \geq m+1, t \leq \frac{m}{m+1}$, then $\left\{k t^{k}\right\}_{k}$ is a strictly decreasing sequence.

4. Proof of the theorem. For any positive integer $m$,

$$
\begin{aligned}
& \frac{a(r)}{\pi}=\sum_{k=1}^{\infty} k\left|c_{k}\right|^{2} r^{2 k} \\
& =\left[m r^{2 m} \sum_{k=1}^{m-1}\left|c_{k}\right|^{2}+\sum_{k=m}^{\infty} k\left|c_{k}\right|^{2} r^{2 k}\right]-\left[m r^{2 m} \sum_{k=1}^{m-1}\left|c_{k}\right|^{2}-\sum_{k=1}^{m-1} k\left|c_{k}\right|^{2} r^{2 k}\right],
\end{aligned}
$$

where $\sum_{k=1}^{0}$ is to be understood to have the value zero; $(23)$ can be rewritten as

$$
\frac{a(r)}{\pi}=\sum_{k=1}^{\infty} \lambda_{k}^{(m)}\left|c_{k}\right|^{2}-\sum_{k=1}^{m-1}\left[\left(m r^{2 m}-k r^{2 k}\right)\left|c_{k}\right|^{2}\right],
$$

where 


$$
\lambda_{k}^{(m)}= \begin{cases}m r^{2 m} & \text { if } 1 \leq k \leq m-1 \\ k r^{2 k} & \text { if } k \geq m\end{cases}
$$

Similarly,

$$
\frac{A(r)}{\pi}=\sum_{k=1}^{\infty} \lambda_{k}^{(m)}\left|C_{k}\right|^{2}-\sum_{k=1}^{m-1}\left[\left(m r^{2 m}-k r^{2 k}\right)\left|C_{k}\right|^{2}\right]
$$

Henceforth let $r$ be positive, and restricted to the interval

$$
\frac{m-1}{m} \leq r^{2} \leq \frac{m}{m+1}
$$

We see by $(25)$ and Lemma $8(\mathrm{v})$ that

$$
\lambda_{1}^{(m)}=\lambda_{2}^{(m)}=\cdots=\lambda_{m}^{(m)}>\lambda_{m+1}^{(m)}>\lambda_{m+2}^{(m)}>\cdots>0
$$

if

$$
\frac{m-1}{m} \leq r^{2}<\frac{m}{m+1}
$$

while, by Lemma 8 (vii),

$$
\lambda_{1}^{(m)}=\lambda_{2}^{(m)}=\cdots=\lambda_{m+1}^{(m)}>\lambda_{m+2}^{(m)}>\lambda_{m+3}^{(m)}>\cdots>0
$$

if

$$
r^{2}=\frac{m}{m+1}
$$

By Lemmas 6 and 6.1, therefore,

$$
\sum_{k=1}^{\infty} \lambda_{k}^{(m)}\left|c_{k}\right|^{2} \leq \sum_{k=1}^{\infty} \lambda_{k}^{(m)}\left|C_{k}\right|^{2} \quad(m=1,2, \cdots)
$$

with equality possible only if

$$
S_{k}=s_{k} \text { for all } k \geq m \text {, providing } \frac{m-1}{m} \leq r^{2}<\frac{m}{m+1} \text {, }
$$


or

$$
S_{k}=s_{k} \text { for all } k \geq m+1 \text {, providing } r^{2}=\frac{m}{m+1} \text {. }
$$

Subtracting ( 26) from (24) gives, by (27),

$$
\frac{a(r)-A(r)}{\pi} \leq \sum_{k=1}^{m-1}\left[\left(m r^{2 m}-k r^{2 k}\right)\left|C_{k}\right|^{2}\right]-\sum_{k=1}^{m-1}\left[\left(m r^{2 m}-k r^{2 k}\right)\left|c_{k}\right|^{2}\right],
$$

with equality possible only if conditions (28) and (29) are met. By Lemma (8) (ii), (iii), and (iv), the last sum of (30) is nonnegative, and can vanish only if

$$
c_{k}=0, k=1,2, \cdots, m-1, \text { providing } \frac{m-1}{m}<r^{2} \leq \frac{m}{m+1},
$$

or

$$
c_{k}=0, k=1,2, \cdots, m-2 \text {, if } r^{2}=\frac{m-1}{m} .
$$

We conclude that

$$
\begin{aligned}
& \frac{a(r)-A(r)}{\pi} \leq \sum_{k=1}^{m-1}\left[\left(m r^{2 m}-k r^{2 k}\right)\left|C_{k}\right|^{2}\right] \\
& \quad=\left(m r^{2 m-2}-1\right) \sum_{k=1}^{m-1} k\left|C_{k}\right|^{2} r^{2 k}-m r^{2 m-2} \sum_{k=1}^{m-1}\left[\left(k r^{2 k}-r^{2}\right)\left|C_{k}\right|^{2}\right] .
\end{aligned}
$$

By Lemma ( 8) (iv), the last sum of (33) is nonnegative, and can vanish only if

$$
C_{2}=C_{3}=\cdots=C_{m-1}=0
$$

Therefore

$$
\begin{aligned}
\frac{a(r)-A(r)}{\pi} & \leq\left(m r^{2 m-2}-1\right) \sum_{k=1}^{m-1} k\left|C_{k}\right|^{2} r^{2 k} \\
& \leq\left(m r^{2 m-2}-1\right) \sum_{k=1}^{\infty} k\left|C_{k}\right|^{2} r^{2 k}=\left(m r^{2 m-2}-1\right) \frac{A(r)}{\pi},
\end{aligned}
$$


where the first inequality sign may reduce to an equality sign only if (28), (29), (31), (32), and (34) hold, while the second inequality may become an equality only if either $m=1$, or $r^{2}=1 / 2$, or

$$
C_{m}=C_{m+1}=\cdots=0, r^{2}>\frac{1}{2} .
$$

From (35) we immediately obtain the desired relation (4). Only the need for examining the possibility of equality in (35) remains.

Collecting the available information for this case, we are led to (5)(iii) when

$$
\frac{m-1}{m}<r^{2}<\frac{m}{m+1}, m \geq 2 .
$$

When

$$
r^{2}=\frac{m}{m+1}, m \geq 2,
$$

on the other hand, we obtain

$$
f(z)=C_{0}+c_{m} z^{m}+c_{m+1} z^{m+1}, F(z)=C_{0}+C_{1} z,
$$

with

$$
\left|C_{1}\right|^{2}=\left|c_{m}\right|^{2}+\left|c_{m+1}\right|^{2} \text {. }
$$

Since $f(z) \prec F(z)$, we also have

$$
c_{m} z^{m}+c_{m+1} z^{m+1} \prec C_{1} z
$$

Therefore, using Lemma 3, we get

$$
\left|c_{m}\right|+\left|c_{m+1}\right| \leq\left|C_{1}\right| \text {. }
$$

Squaring (37), and subtracting (36), yields the conclusion that either $c_{m}=0$ or $c_{m+1}=0$, and therefore (5) (iv) follows.

For $r^{2} \leq 1 / 2$ we know that 


$$
\sum_{k=1}^{n}\left|c_{k}\right|^{2}=\sum_{k=1}^{n}\left|C_{k}\right|^{2}
$$

For $r^{2}<1 / 2$, from Lemma 6.1 it is found to be necessary that $\omega(z)=\eta z$, as was already shown by Goluzin.

The only remaining case is $r^{2}=1 / 2$. Again $\omega(z)=\eta z$ gives equality in (3). We leave this trivial possibility aside by restricting our attention (see Lemma 1 ) to

$$
\left|c_{1}\right|<\left|C_{1}\right|,\left|\beta_{1}\right|<1 \text {. }
$$

Applying Lemma 5 to (38) yields

$$
c_{k}=\beta_{1}^{k} C_{k}
$$

$$
(k=3,4, \ldots),
$$

or, by (38) and (40),

$$
\left|c_{k}\right|=\left|\beta_{1}\right|^{k}\left|C_{k}\right|=\left|C_{k}\right|
$$

Therefore, in view of (39),

$$
c_{k}=C_{k}=0
$$

This shows that $f(z)$ and $F(z)$ are respectively of the forms

$$
f(z)=c_{0}+c_{1} z+c_{2} z^{2} \text { and } F(z)=c_{0}+C_{1} z+C_{2} z^{2} \text {. }
$$

Equations (38) and (41) contain the hypotheses of Lemma 7, and the result (5) (ii) of the theorem therefore follows.

In conclusion, it may be remarked that due to Lemma (8)(i), the function $T(r)$ may be written in the compact form

$$
T(r)=\max _{k=1,2, \ldots}\left(k r^{2 k-2}\right) \quad(0<r \leq 1) .
$$

As an immediate consequence, we have the much weaker result that

$$
T(r)<\sum_{k=1}^{\infty} k r^{2 k-2}=\frac{1}{\left(1-r^{2}\right)^{2}}
$$




\section{REFERENCES}

1. G. M. Goluzin, On majorants of subordinate analytic functions I, Mat. Sbornik, N.S. 29 (1951), $209-224$.

[ Г. М. Голувин, о мажораиии подииненных аналитиееских сууниии. I Математическии Сборник, Н. С.29 (1951), 209-224.]

2. J. E. Littlewood, Lectures on the theory of functions, London, 1944.

3. W. Rogosinski, On the coefficients of subordinate functions, Proc. London Math. Soc. 2, 48 (1943), 48-82.

RAND CORPORATION AND

University of California, Los Angeles 


\section{PACIFIC JOURNAL OF MATHEMATICS}

\section{EDITORS}

\author{
M.M. SCHIFFE R* \\ Stanford University \\ Stanford, California \\ E. HEWITT \\ University of Washington \\ Seattle 5, Washington
}

\author{
R.P. DILWORTH \\ Calif ornia Institute of Technology \\ Pasadena 4, California \\ E. F. BECKENBACH** \\ University of California \\ Los Angeles 24, California
}

\section{ASSOCIATE EDITORS}

$\begin{array}{llll}\text { H. BUSEMANN } & \text { P.R. HALMOS } & \text { BØRGE JESSEN } & \text { J. J. STOKER } \\ \text { HERBERT FEDERER } & \text { HEINZ HOPF } & \text { PAUL LÉVY } & \text { E. G. STRAUS } \\ \text { MARSHALL HALL } & \text { R.D. JAMES } & \text { GEORGE PÓLYA } & \text { KÔSAKU YOSIDA }\end{array}$

\section{SPONSORS}

UNIVERSITY OF BRITISH COLUMBIA

UNIVERSITY OF SOUTHERN CALIFORNIA

CALIFORNIA INSTITUTE OF TECHNOLOGY

UNIVERSITY OF CALIFORNIA, BERKELEY

STANFORD RESEARCH INSTITUTE

UNIVERSITY OF CALIFORNIA, DAVIS

STANFORD UNIVERSITY

UNIVERSITY OF CALIFORNIA, LOS ANGELES

WASHINGTON STATE COLLEGE

UNIVERSITY OF CALIFORNIA, SANTA BARBARA

UNIVERSITY OF WASHINGTON

UNIVERSITY OF NEVADA

OREGON STATE COLLEGE

AMERICAN MATHEMATICAL SOCIETY

UNIVERSITY OF OREGON

HUGHES AIRCRAFT COMPANY

Mathematical papers intended for publication in the Pacific Journal of Mathematics should be typewritten (double spaced), and the author should keep a complete copy. Manuscripts may be sent to any of the editors. Manuscripts intended for the outgoing editors should be sent to their successors. All other communications to the editors should be addressed to the managing editor, E.G. Straus, at the University of California Los Angeles 24, California.

50 reprints of each article are furnished free of charge; additional copies may be obtained at cost in multiples of 50 .

The Pacific Journal of Mathematics is published quarterly, in March, June, September, and December. The price per volume (4 numbers) is $\$ 12.00$; single issues, $\$ 3.50$; back numbers (Volumes $1,2,3$ ) are available at $\$ 2.50$ per copy. Special price to individual faculty members of supporting institutions and to individual members of the American Mathematical Society: $\$ 4.00$ per volume; single issues, $\$ 1.25$.

Subscriptions, orders for back numbers, and changes of address should be sent to the publishers, University of California Press, Berkeley 4, California.

Printed at Ann Arbor, Michigan. Entered as second class matter at the Post Office, Berkeley, California.

* To be succeeded in 1955, by H.L. Royden, Stanford University, Stanford, California.

** To be succeeded in 1955, by E.G. Straus, University of California, Los Angeles 24, Calif.

UNIVERSITY OF CALIFORNIA PRESS - BERKELEY AND LOS ANGELES

COPYRIGHT 1954 BY PACIFIC JOURNAL OF MATHEMATICS 


\section{Pacific Journal of Mathematics}

\section{Vol. 4, No. $2 \quad$ June, 1954}

Henry Ludwig Alder, Generalizations of the Rogers-Ramanujan

identities ........................................ 161

E. M. Beelsey, Concerning total differentiability of functions of class $P$. . . 169

L. Carlitz, The number of solutions of some special equations in a finite

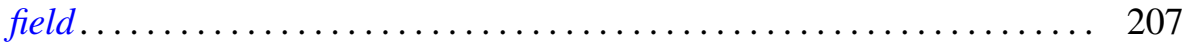

Marshall Hall, On a theorem of Jordan ............................ 219

J. D. Hill, Remarks on the Borel property..................... 227

Joseph Lehner, Note on the Schwarz triangle functions ............... 243

Arthur Eugene Livingston, A generalization of an inequality due to

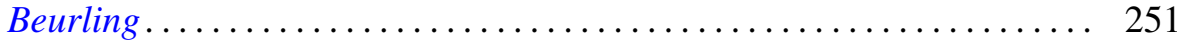

Edgar Reich, An inequality for subordinate analytic functions .......... 259

Dan Robert Scholz, Some minimum problems in the theory of functions ... . 275

J. C. Shepherdson, On two problems of Kurepa ................. 301

Abraham Wald, Congruent imbedding in F-metric spaces ............ 305

Gordon L. Walker, Fermat's theorem for algebras ............... 317 